\title{
Study on Retrofitting of RCC Column using Ferro Cement
}

\author{
Saurav Kumar ${ }^{1}$, Vivek Kumar ${ }^{1}$, Anuj Kumar ${ }^{1}$ \\ Chandan Kumar ${ }^{2}$, Dr. Krishna Murari ${ }^{3}$ \\ ${ }^{1}$ UG Student, Dept. of Civil Engineering, NSIT Bihta, Patna (India) \\ ${ }^{2}$ Assistant Professor, Dept. of Civil Engineering, NSIT Bihta, Patna (India) \\ ${ }^{3}$ Professor, Dept. of Civil Engineering, BIT Sindri, Dhanbad (India)
}

\begin{abstract}
Past devastating earthquakes have proven the vulnerability of most low strength buildings and the need for seismic strengthening through existing remedial measures that are inexpensive and not beyond the skills of local building industries.

Strengthening of existing reinforced concrete (RC) members is of great importance. Many techniques such as concrete jacketing, steel jacketing, steel skeleton and composite (FRP) are used. The present study focuses on strengthening column subjected to compression load. A new smart technique by adding external steel bars in tension side of the column wrapped with steel wire mesh jacket is presented and examined.

Ferrocement is the construction material consisting of wire meshes and cement mortar application of Ferrocement in constructions vast due to the low self-weight, lack of skilled workers, etc. Retrofitting is the process of increasing the seismic resistance of damaged or weak structure by appropriate techniques. Retrofitting of earthquake damaged structure is done by repairing and strengthening the damaged portions of the structure and making it reusable.

Ferrocement used as retrofitting due to their easy availability, economy, durability and their property of being cast to any shape without needing significant formwork. In present work the square welded wire mesh $(1.16 \mathrm{~mm}$ diameter and grid $15 \mathrm{~mm} \times 15 \mathrm{~mm})$ is use in the specimens to increase the compressive strength and providing 2-3 layers of ferrocement jacketing. We were cast the RCC column and square welded wire mesh used in it. We tested the under compressive loading and got a result that compressive strength of square welded wire mesh column higher than the normal column.
\end{abstract}

Keywords: Ferrocement, Retrofitting, Seismic resistance, Square welded wire mesh, Compressive Load.

\section{- General}

\section{INTRODUCTION}

The RCC structures constructed in the developed world are often found to show suffer damage, even before there service period due to some causes such as improper design, change of use of building, faulty construction, change in code provision, earthquakes, explosion, wear and tear, flood, fire, etc. such structure requires immediate repair or maintenance and suitable remedial measures, so as to bring such structure into its functional use again by suitable retrofitting and strengthening techniques. The Columns is the most important structural member in any structure that transfers the entire loads to the foundation. Reinforced columns in a structure get dam aged due to various reasons like overloading, corrosion of steel, earthquake, higher wind loads, fire, impact loads, etc. Therefore, the strengthening of deficient columns is necessary to increase the load carrying capacity and prevent spelling which can be achieved by confinement of column externally. Jacketing is one of the most popular and economical method for strengthening of columns. Some of the materials that are used in the jacketing of columns are ferrocement, glass fiber, carbon fiber, etc. Ferrocement is a special form of reinforced concrete which exhibits uniform dispersion of reinforcement in matrix offers improved tensile and flexural strength, fracture, toughness, crack control and impact resistance.

The vast majority of earthquake fatalities in the last century have resulted from building failures in developing countries like Nepal. The greatest risk is by far presented to inhabitants of non-engineered low strength masonry structures as demonstrated in the earthquakes of Bam, Iran (2003), Pakistan (2005), and Pisco Peru (2007), where many of the thousands of deaths were attributable to vulnerable low strength structures.

To restore the required strength of the deteriorated structure, retrofitting is the solution.

Retrofitting can be done in two ways as shown in (figure 1):

- Global Retrofitting.

- $\quad$ Local Retrofitting.

In Global Retrofitting, entire structure is retrofitted to fulfill serviceability requirements. It involes the analysis and design of entire structure as per specification given in the standard codes.whereas, in Local Retrofitting, only specific member of the structure is either strengthened or replaced. 


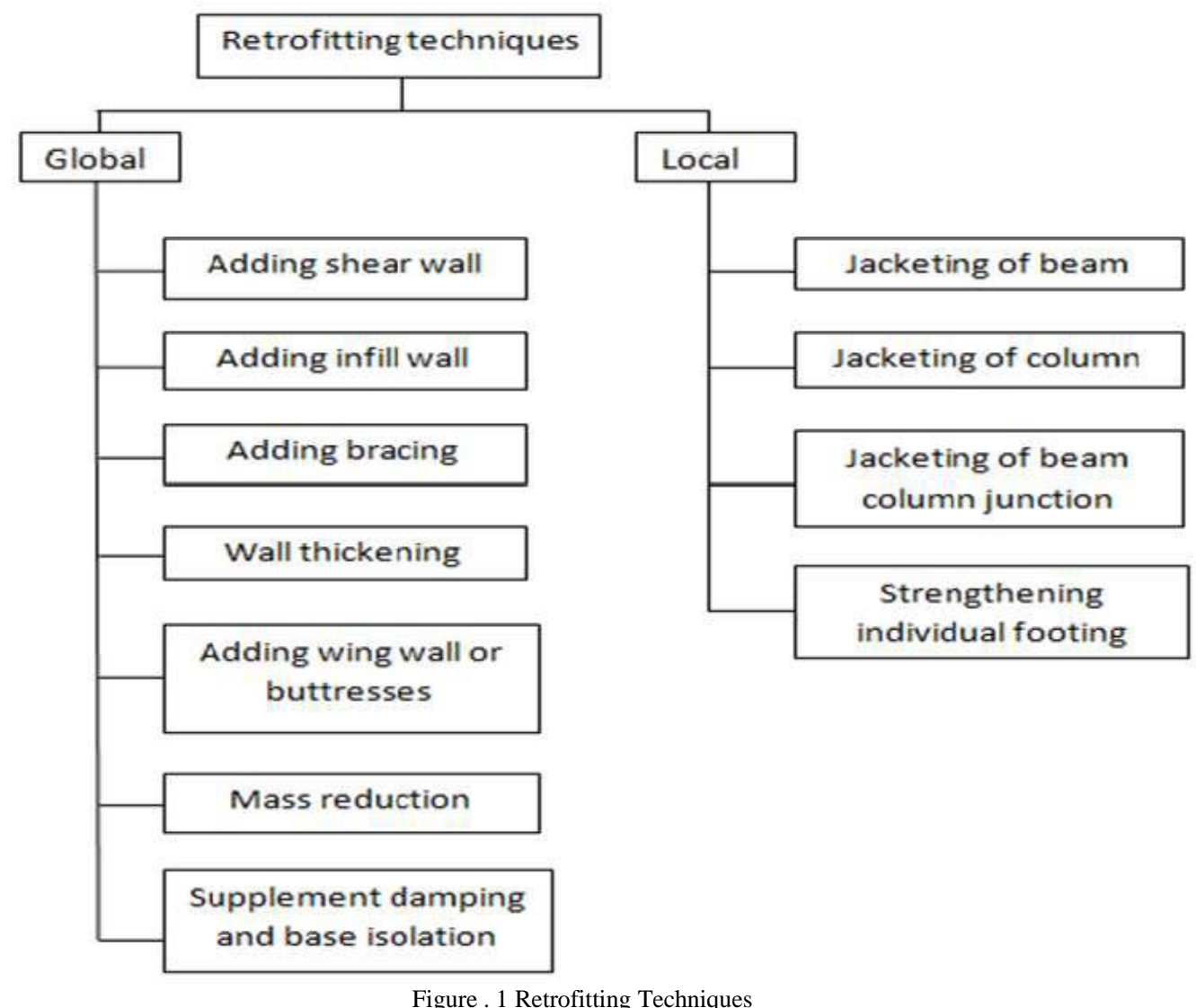

Retrofitting with ferrocement confinement is the oldest and cost effective technique used to strengthen the concrete structures. ferrocement consist of closely-spaced and uniformaly distributed reinforcement which provides ductility to the otherwise brittle concrete.

\section{- Ferrocement-a composite material}

Ferrocement is a type of thin reinforced wall commonly constructed of hydraulic cement mortar reinforced with closely spaced layers of continuous and relatively small size wire mesh (ACI Committee 549-R97, 1997). In-situ casting of ferrocement structures consists of high cement content, low water cement ratio around 0.4 , wire mesh layers, light structural steel, admixtures like silica fume, super plasticizers and non-metallic fibers. This makes ferrocement structures high strength to weight ratio. Therefore, self-weight of ferrocement structure is very less as compared to RCC. In its role as a thin reinforced concrete product and as laminated cement-based composite, ferrocement has found itself in numerous applications both in the construction of new structures and repair/rehabilitation of existing structures. Compared with conventional reinforced concrete, ferrocement is reinforced in two directions; therefore, it has homogenous isotropic properties in two directions. Due to these properties, ferrocement shows a high tensile strength and high modules of rupture. Ferrocement is highly waterproof, crack formation resistant, energy absorbing material. During earthquake, the forces at nodal points of ferrocement structures are less accordingly thereby decreasing the damage and devastation. Structural members confined with ferrocement such as beams, columns develop first crack at high value of force reasonably above the elastic point. In addition, because the specific surface of ferrocement reinforcement is higher than that of reinforced concrete, larger bond forces develops with matrix resulting in average crack spacing and crack width of smaller magnitude than that of conventional reinforced concrete. Other unique features of ferrocement include ease of fabrication and low cost in maintenance and repair. Based on these advantages, ferrocement can be effectively utilized for strengthening or retrofitting such as water tanks, boats, housing wall panels, roofs, form work.

\section{- Wire mesh}

Ferrocement uses layers of continuous/ small diameter steel wire/ welded mesh (metallic or non-metallic) as reinforcement with high volume fraction ( 2 to $8 \%$ ) and the specific surface of reinforcement is considerably higher for ferrocement than for RCC. 


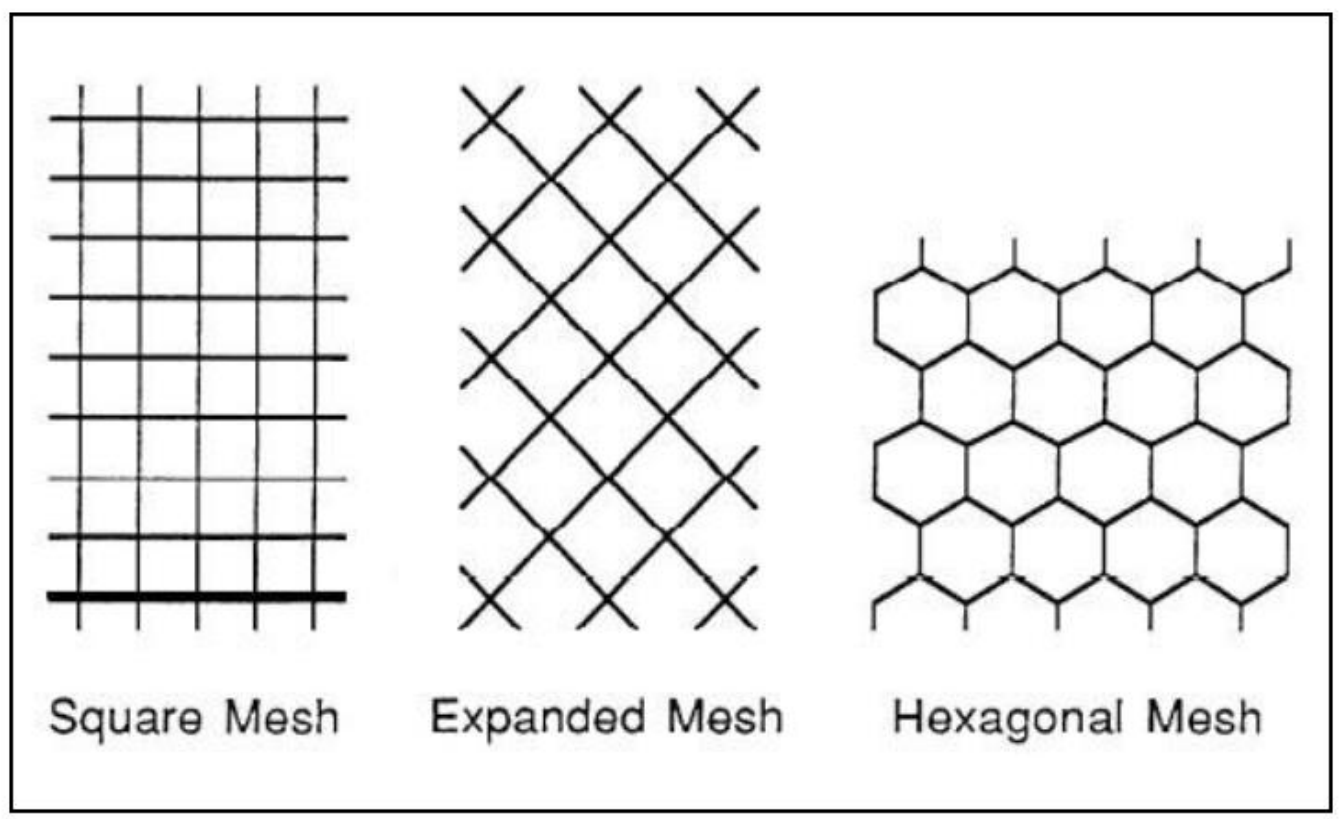

Figure . 2 Types of Wire Mesh

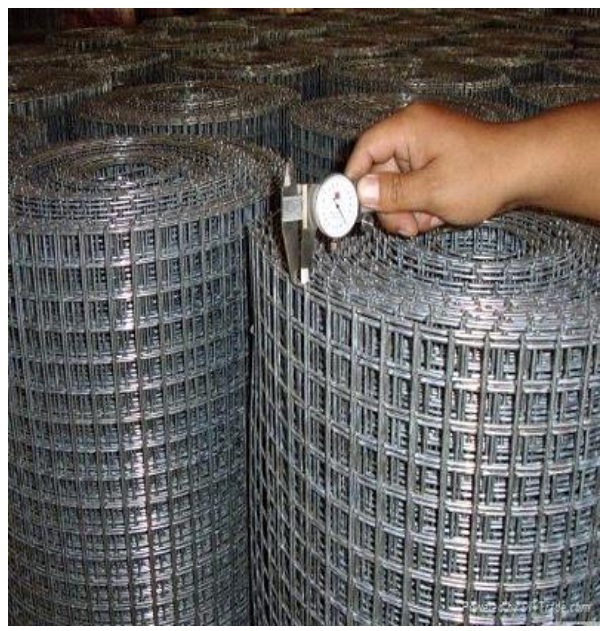

Figure . 3 Galvanized Wire Mesh

Also, the reinforcing steel wire mesh has openings large enough for adequate bonding; the closer distribution and uniform dispersion of reinforcement, transform the otherwise brittle mortar into a high performance material distinct from reinforced concrete. Skeletal of the structure to be built is made first with bars or wires, which are used as spacer material and the mesh layers are later attached to skeletal.

\section{- Advantages of Ferrocement Technology}

- Ferrocement is an isotropic material up to $40 \%$ of the yield and its density is about $2750 \mathrm{~kg} / \mathrm{m}^{3}$. $\mathrm{RCC}$ material is a heterogeneous material (density $2500 \mathrm{~kg} / \mathrm{m}^{3}$ ) consists of voids and capillaries. Therefore, water and other gases easily entrapped in the concrete material which cause crack formation, spalling and corrosion of reinforcement. Moreover, the cracks formed over RCC structures are wide and deep whereas minute and shallow cracks are formed in the ferrocement structures. Structural members of ferrocement remain free of voids and capillaries hence remain corrosion resistant and water proof due to these properties.

- Ferrocement has high strength to weight ratio. Ferrocement is thin section high strength structural material highly waterproof, crack formation resistant, energy absorbing material. It is manufactured with high cement content, low water cement ratio around 0.4 , wire mesh layers, light structural steel, admixtures mainly silica fume super plasticizers, non-metallic fibers, particularly when ferrocement is cast-in- situ. Therefore self-weight of ferrocement structure is very less as compared to RCC.

- Ferrocement is highly ductile, resilient, energy absorbing material. When put under load it develops cracks at a much higher value after the elastic limit. Because of this property a ferrocement structures frame will not collapse like RCC and therefore there will be least loss of life and property. Ferrocement structures do not 
collapse but get deformed. A large number of such structures as compared to RCC can be easy to repair. The debris formation will also be the less.

\section{- Column-the Authoritative Structural Element}

Column is the most authoritative structural element because it carries the entire load of the structure. The failure of the column leads to the total collapse of the whole frame structure as it transmits the vertical loads to the foundation. Columns may be cast to any of the following shapes,

- Square

- Rectangular

- Circular

- Hexagonal

The effective length of the column depends on the degree of fixity of the ends of the columns. IS 456:2000 provides recommendations for the effective length of the compression members as shown in Figure 3. The different end conditions govern the behavior of column in different loading conditions.

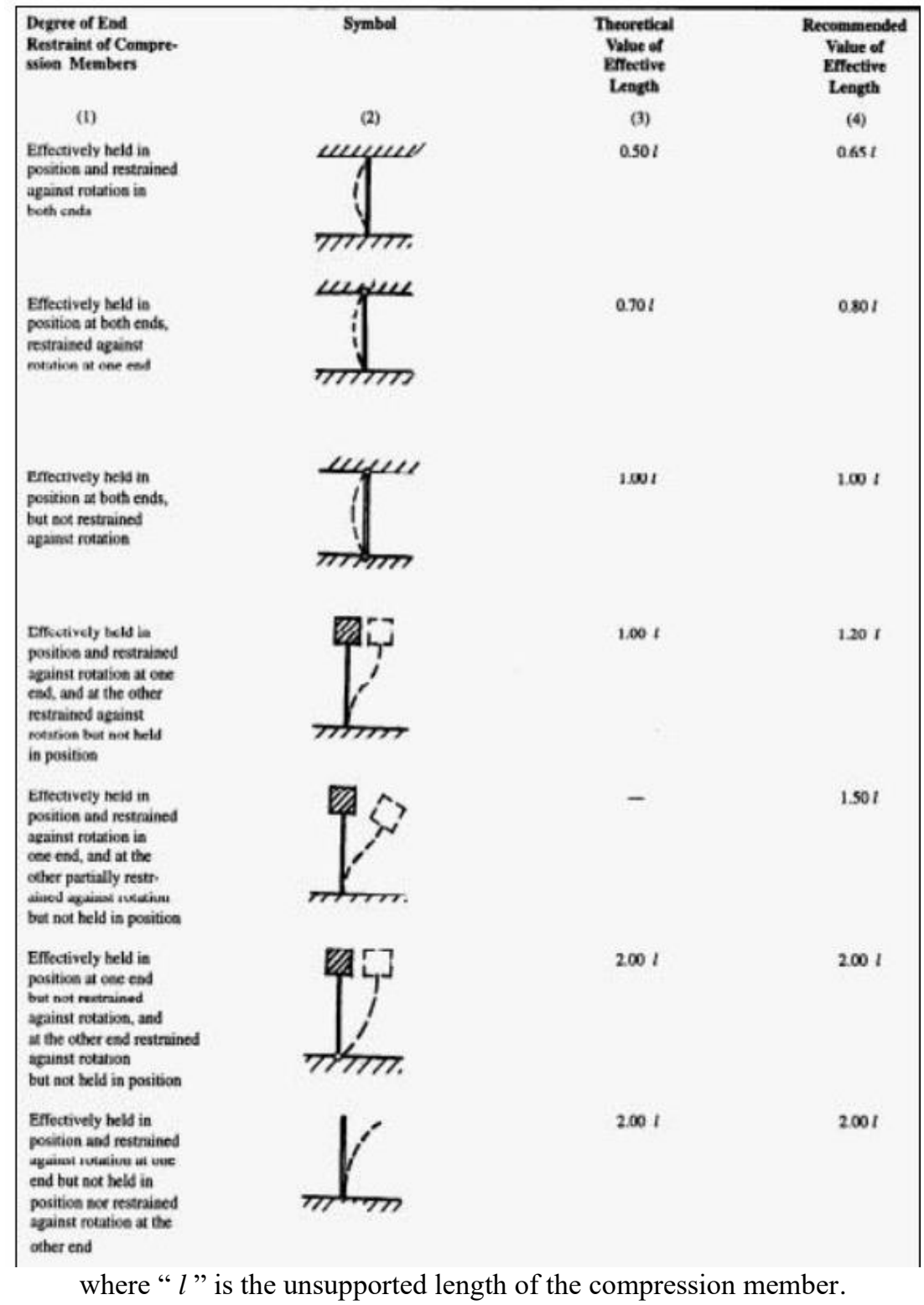

Figure. 3 Effective Length of Compression Members

As the effective length of the column increases, the load carrying capacity is influenced by the end conditions. The columns are classified on the basis of slenderness ratio $(\square)$ into two categories as under: 
- Short Column

- Long Column

Slenderness ratio $(\square)$ is the ratio of length to diameter/ least lateral dimension. If the value of slenderness ratio ( $\square$ ) is less than 12, the column is considered as Short Column and if the value is greater than 12, the column it is considered as a Long Column. The short column has more load carrying capacity than the long column of the same cross section.

Retrofitting or reconstruction of the cracked or corrosive column is the necessary task to prevent the further damage to the whole structure. External confinement of the RC column increases the ultimate load carrying capacity and imparts ductility to the core concrete. The strength of the column is greatly influenced by the length.

The mode of failure of the short column is mostly in compression whereas the long columns fail with a buckling mode. The slenderness ratio governs the mode of failure. In compression mode of failure, the column has a tendency of failure either near the top or bottom of the column with a brittle fracture followed by the rupture of the core concrete. Long columns fail near the middle of the length showing large lateral deflection as compared to small deflection exhibited by the short columns.

\section{Materials}

\section{MATERIALS AND METHODS}

- Steel Skeleton This is used for making framework of structural component upon which layers of wire mesh reinforcement are laid.

- Wire Mess.

- Cement Mortar:

- Cement: OPC or PPC is used of Grade-53

- Sand: Well graded natural river sand with particle size less than $4.75 \mathrm{~mm}$ having fineness modulus between 2.5 to 3.0

- Cement sand mix - 1:1.5 to $1: 3$

- Water cement ratio - 0.35 to 0.55

- $5 \%$ of Plasticizers and other admixtures are used*

\section{Methods}

- Literature review on Ferro cement slabs.

- Study of code provisions.

- Collection of welded mesh and other ingredients.

- Preliminary tests on materials.

- Design of mortar mix.

- Jacketing with Ferro cement on RCC column.

- Tensile and compressive strength testing.

- Toughness and energy of all specimens to be calculated.

- Analysis of the test results.

- Comparison of the results obtained.

- Conclusion.

\section{RCC COLUMNS:}

Details of both benchmark and jacketed column specimens are shown in Figure 4. 


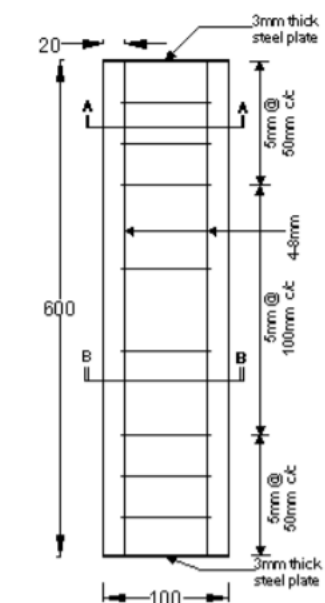

(a)

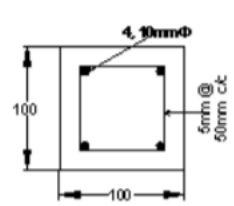

(c)

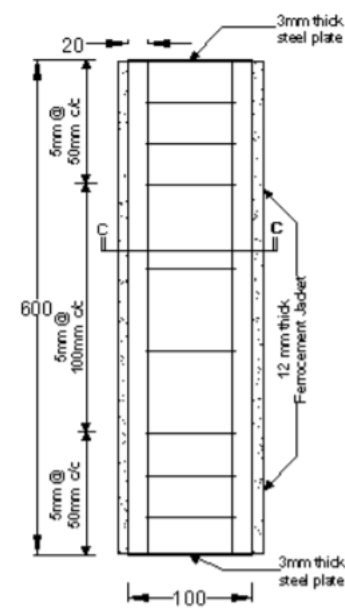

(b)

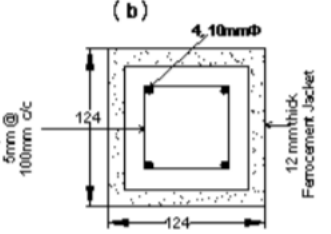

(e)

Figure 4. Column specimen details, (a) Non-jacketed column, (b) Ferrocement jacketed column, (c) Section A-A, (d) Section B-B, (e) Cross-section C-C.

Short column specimen of size $600 \mathrm{~mm}$ long and cross section of 100x100 mm² was taken. 4- 8mm (dia.) deformed longitudinal reinforcements and $5 \mathrm{~mm}$ (dia.) seismic tie bar spaced at $100 \mathrm{~mm}$ in middle and $50 \mathrm{~mm}$ at top-bottom were placed in all specimens. Cement and aggregates were mixed manually and thoroughly in dry state first, and then water was added and mixed uniformly. Workability of concrete was checked by slump test. Column specimens were then cast and it was de-moulded after 24 hours of casting.

\section{CASTING OF REINFORCED CONCRETE COLUMN SPECIMENS}

Cement Concrete is a mixture of well proportioned cement, coarse aggregates, fine aggregate and water. For the reinforcement steel bars of various diameters are used and for confinement with ferrocement GI wire mesh was used. The grade of design concrete mix was M20. The column samples in three size groups; nine columns of (100 x $100 \times 300 \mathrm{~mm}, \square=3$ ), nine columns of (100 x 100 $\mathrm{x} 700 \mathrm{~mm}, \square=7)$ and nine columns of $(100 \times 100 \mathrm{x} 1500 \mathrm{~mm}, \square=15)$ were casted. Each column was reinforced with 4 bars of $8 \mathrm{~mm}$ diameter as longitudinal reinforcement and 6mm diameter stirrups @ 150mm c/c. The reinforcement used was of Fe 415 grade. For each group, three columns were kept as control samples. Six samples from each were hand chiselled to obtain a rough surface. After surface cleaning, three columns were confined with one layer of steel wire mesh and three columns were confined with two layers of GI wire mesh in each group.

\section{FERROCEMENT JACKETING:}

RC columns were jacketed with different types of ferrocement jacketing after 7 days of casting. Final size of jacketed specimens was $124 \mathrm{~mm}$ including $12 \mathrm{~mm}$ ferrocement jacket. 20 BWG (British Standard Wire Gauge) woven GI (Galvanized Iron) wire mesh of $12 \mathrm{~mm}$ square opening was used in this study. Wire mesh was kept at the middle of jacket layer with a covering of $6 \mathrm{~mm}$ in both exterior and interface surfaces.

A gap of $3 \mathrm{~mm}$ was kept at both the top and bottom of the specimen to avoid direct compression on the ferrocement jacket. All columns, after completing jacketing work, were cured in the water for 28 day from the date of casting.

\section{CONFINEMENT OF COLUMN SAMPLES WITH FERROCEMENT}

For the confinement of the concrete column with ferrocement, the surface of the samples was hand-chiselled and any dust or loose particles were removed with washing and allowed to air dry. After surface preparation column samples were wrapped with one layer of GI wire mesh followed by the application of layer of cement mortar $25 \mathrm{~mm}$ thick to achieve a square width of $150 \mathrm{~mm} \mathrm{x}$ $150 \mathrm{~mm}$.

In the second phase of experiment, column samples were wrapped with two layers of GI wire mesh with continuous wrapping with overlapping of second layer followed by plastering with cement mortar of $25 \mathrm{~mm}$ thickness to achieve a width of $150 \mathrm{~mm} \times 150 \mathrm{~mm}$ on all faces. Proper curing is necessary to develop the required strength of the mortar. A curing period of 28 days is suggested; 
however, at least curing in the first two weeks is essential and should start 24 hours after final application of the mortar to avoid shrinkage cracks.

\section{TESTING OF SPECIMENS}

After curing, all columns are tested under monotonically increasing concentric load applied at the top with a hydraulic compression testing machine of capacity $2000 \mathrm{kN}$. Both benchmark and jacketed specimens are tested until failure. Axial deflection and lateral bulging of columns were measured using dial gauges within the accuracy of $0.0001 \mathrm{inch}(0.00254 \mathrm{~mm})$. Test set up and the positions of dial gauges are shown in Figure 5.

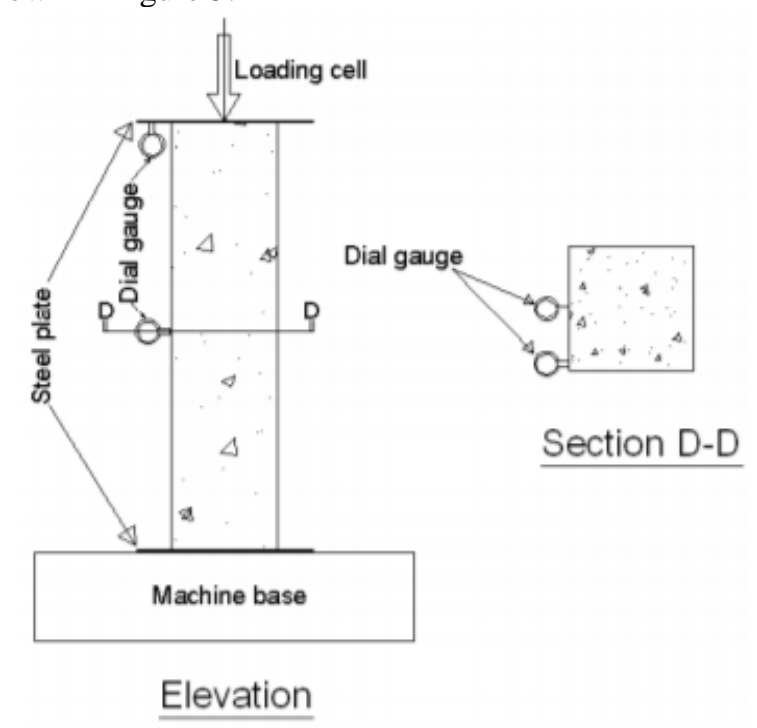

Figure 5. Test setup and Dial Gauge positions.

DESIGN OF MORTAR MIX: The following mix is to be used to prepare the motor, which is shown in table no- 1 .

Table 1 .mix design

\begin{tabular}{|c|c|c|c|c|}
\hline Variables & Sand/Cement ratio & Water/Cement ratio & $\begin{array}{c}\text { volume of cement } \\
\left(\mathbf{k g} / \mathbf{m}^{\mathbf{3})}\right.\end{array}$ & $\begin{array}{c}\text { Volume of fine aggregate } \\
\left(\mathbf{k g} / \mathbf{m}^{\mathbf{3})}\right.\end{array}$ \\
\hline Ferrocement & $1: 2$ & 0.45 & 678 & 1357 \\
\hline RCC & $1: 1.32: 2.2$ & 0.45 & 492.5 & 651 \\
\hline
\end{tabular}

RESULTS

The compressive strengths of concrete and mortar mix for 7, 14, 28 days are shown in (Fig.6). All casted cubes of concrete and mortar are tested in compressive testing machine which has a capacity of 200 ton. Total of 27 cubes ( 9 cubes for concrete and 18 cubes for mortar) were tested to find the compressive strength. To find the best matrix two trial mixes were used. Concrete achieved a strength of $32.6 \mathrm{~N} / \mathrm{mm} 2$ and mortar mix achieved a compressive strength of $37.4 \mathrm{~N} / \mathrm{mm} 2$ after curing of 28 days. Experimental results for cube were shown below in figure 6.

Conventional column has achieved a compressive strength of $236 \mathrm{KN}$ with a deflection of $1.62 \mathrm{~mm}$. Failure of Ferro cement solid columns takes place along the periphery of specimen, diagonal cracks were observed and spalling of mortar takes place instead of buckling welded mesh. 


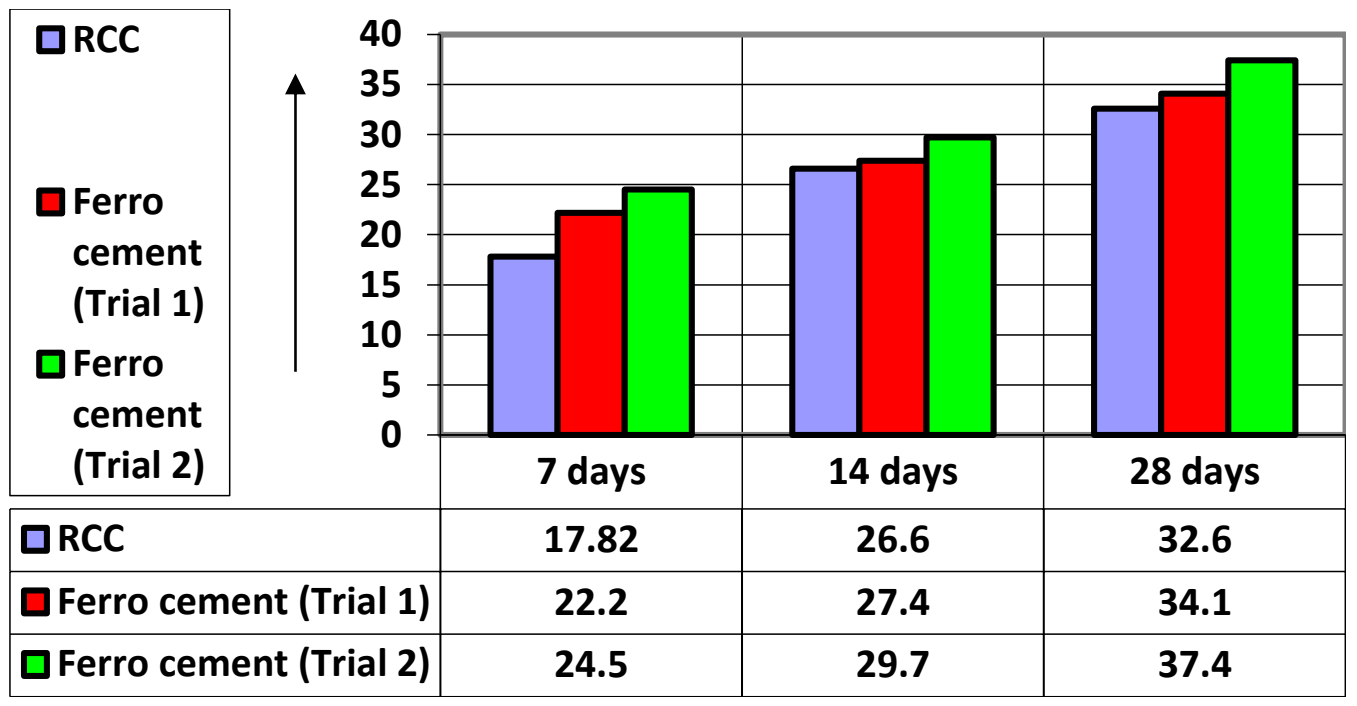

(where compressive strength is $\mathrm{N} / \mathrm{mm}^{2}$ )

Figure 6 . comparing compressive strength for 7, 14, and 28 days.

The collapse load thus determined for all columns were shown in Table 2. Load vs. deflection graphs were plotted for all the tested specimens are shown in (Fig. 7). Ferro cement hollow column carries a load of $272 \mathrm{KN}$ with a deflection of $2.86 \mathrm{~mm}$. By increasing number of layers of weld wire mesh compressive strength increased and initial deflection got minimised.

Table 2. comparison of collapse load for RCC and ferro cement columns

\begin{tabular}{|l|c|c|c|c|}
\hline Specimen & RCC & Ferro cement Hollow & $\begin{array}{l}\text { Ferro cement (1 layer } \\
\text { of mesh) }\end{array}$ & $\begin{array}{l}\text { Ferro cement } \\
\text { layers of mesh) }\end{array}$ \\
\hline Dimensions (mm) & $110 \times 110 \times 1000$ & $110 \times 110 \times 1000$ & $110 \times 110 \times 1000$ & $110 \times 110 \times 1000$ \\
\hline Reinforcement details & & & & $1.26 \mathrm{~mm}$ GI mesh \\
\hline Grades of mix & M4,8Ø & $1.26 \mathrm{~mm}$ GI mesh & $1.26 \mathrm{~mm}$ GI mesh & M30 \\
\hline Ultimate load (KN) & 236 & M30 & M30 & 324 \\
\hline Deflection (mm) & 1.62 & 272 & 252 & 2.28 \\
\hline
\end{tabular}

Load vs. deflection graphs were plotted for all the tested specimens are shown in (Fig. 7).

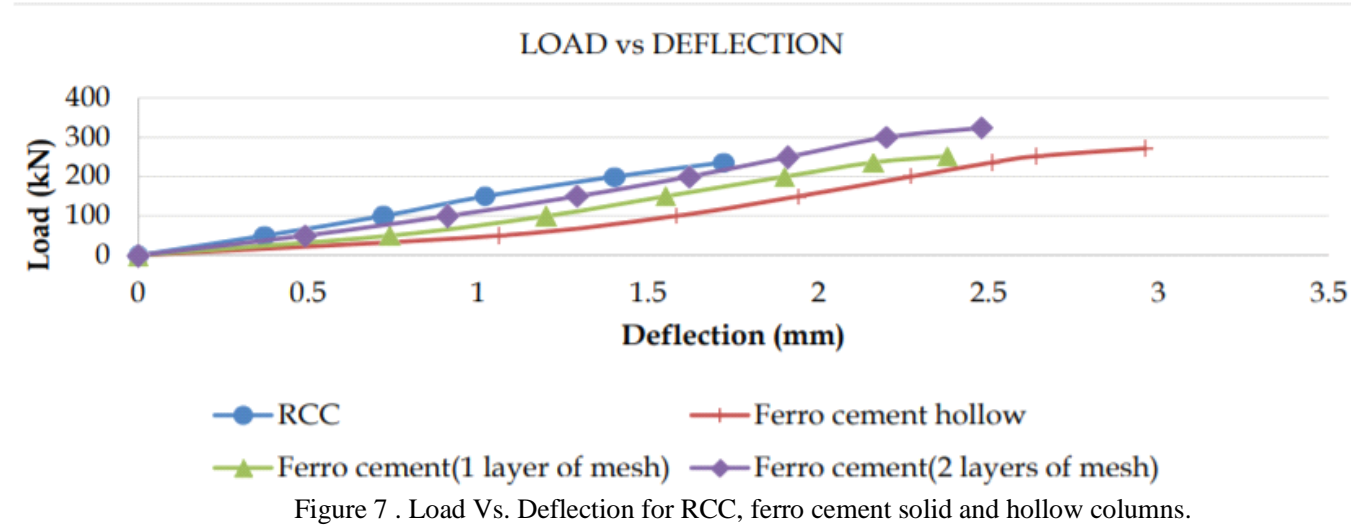

CONCLUSION AND SUMMARY

The used retrofitting and strengthening technique is successful for damaged columns to improve the loadcarrying capacity under to eccentric loads. From the experimental results the followings are concluded:

- The increase in eccentricity from e/t= $0 \%$ to $25 \%$ decreases the ultimate load carrying capacity of columnsby $93 \%$ to $71 \%$ from column carrying capacity $\mathrm{e} / \mathrm{t}=0$.

- The percentage of forces on the internal vertical steel bars at eccentricity direction decreases about 5\% whilethe strain increases about $25 \%$.

- Ferrocement jacketing improves the ultimate load carrying capacity and increases the ultimate axial deflection of RC 
column.

- Based on test results, by increasing layers of weld mesh the compressive strength of columns increased.

- Ferrocement confinement increased the ultimate load carrying capacity of columns.

- With the increase in slenderness ratio of columns the strength provided by ferrocement confinement decreases. In short column ( $\square=3$ ) confinement with one layer of wire mesh increased the strength up to $92 \%$ as compared long column ( $\square=15$ ) which exhibited an increase of only $36 \%$

- Lateral deflections are significantly minimised with ferrocement confinement up to first layer of wire mesh but there is marginal decrease with second layer.

- Ultimate load capacity of control sample is increased with single layer up to $92 \%$ and with two layers it increased to $102 \%$ which is marginal.

\section{REFERENCES}

[1] IAETSD JOURNAL FOR ADVANCED RESEARCH IN APPLIED SCIENCES VOLUME 4, ISSUE 7, DEC/2017 ISSN NO: $2394-8442$-Retrofitting of reinforced column by using ferrocement jacketing-Hiralal Pawar1, Sagar Chavan2, Abhijeet Padade3, Govind Mhaske4.

[2] International OPEN ACCESS Journal Of Modern Engineering Research (IJMER)-Retrofitting and Strengthening of Damaged ReinforcedConcrete Columns Using Steel Angels Wrapped with SteelWire Mesh-Abd-ELhamed, M. K.1, Ezz-Eldeen, H. A.2

[3] A Rajasekaran, PN Raghunath, and K Suguna (2008), Effect of confinement on the axial performance of fiber reinforced polymer wrapped RC column, American Journal of Engineering and Applied Sciences 1 (2): pp. 110-117.

[4] The 2nd International Conference on Rehabilitation and Maintenance in Civil Engineering Ferrocement Jacketing for Restrengthening of Square Reinforced Concrete Column under Concentric Compressive Load A. B. M. Amrul Kaisha*, M. R. Alamb, M. Jamilc and M. A. Wahedd.

[5] EXPERIMENTAL INVESTIGATION ON FERRO CEMENT COLUMNS UNDER STATIC LOADING M.PAVAN KUMAR1* AND S PRADEEP2-Jr. of Industrial Pollution Control 33(S3)(2017) pp 1469-1474 Research Article

[6] Ivy, F.H. (2013). Behavior of reinforced concrete columns confined with high-performance ferro cement. ASCE. 139(4) : 574-583. 